\title{
DESCARTES Y LOS INICIOS DE LA LÓGICA FACULTATIVA
}

\author{
Rafael Cerpa Estremadoyro* \\ Universidad Nacional Autónoma de México \\ rafael.cerpa@comunidad.unam.mx
}

RESUMEN: Las objeciones a la silogística por parte de Descartes se desarrollan al mismo tiempo que él presenta nuevos alcances acerca de la naturaleza de la inferencia y del descubrimiento científico. Es por esto que estudiaremos primero su concepción de la inferencia, llamada facultativa por algunos autores. Después, analizaremos las críticas formuladas por este autor contra el silogismo, el cual, además de ser inválido por ser una forma de petición de principio, no contribuye en nada al descubrimiento científico e incluso puede ser perjudicial para el ejercicio espontáneo de la razón.

Palabras Clave: Descartes, lógica, inferencia, intuición, método científico.

\section{DESCARTES AND THE BEGINNING OF FACULTATIVE LOGIC}

Abstract: Objections to syllogistic were developed by Descartes at the same time he provided new insights regarding the nature of inference and

* Rafael Cerpa Estremadoyro ha realizado estudios doctorales y máster en Historia de la Filosofía por la Universidad París-Sorbona (Francia). En 1997, fue acreedor de una beca por parte del Instituto Nacional de Becas del Estado griego (becas YKY) para realizar estudios en la Universidad de Atenas. Sus temas de investigación se orientan principalmente a la filosofía antigua, filosofía latinoamericana, epistemología, historia de la lógica y metafísica tanto antigua como contemporánea. Se ha desempeñado como docente en diferentes universidades del Perú. Ha sido consultor-editor en la Sección Historia y Cultura de la UNESCO (París). Ha participado como ponente y conferencista en diversos eventos a nivel nacional e internacional. 
scientific discovery. This is why the following paper first focuses on the Cartesian conception of inference known as facultative by some interpreters. Thereafter, we will analyze the criticisms raised by the author against syllogism which is not only invalid for being a form of principle request but its null contribution to the scientific discovery may be even harmful for spontaneous exercise of reason.

KeYwords: Descartes, logic, inference, intuition, scientific method.

\section{INTRODUCCIÓN}

Es conocida la carta de Descartes al sacerdote jesuita E. Charlet, antiguo rector de la Flèche, donde él afirma que su filosofía no considera ningún principio que no se encuentre en la filosofía de Aristóteles. ${ }^{1}$ En un escrito anterior, incluso él está presto a reconocer la importante herencia de los «fundadores originales de la filosofía», aunque no cita a Aristóteles entre ellos, sino a Platón, creador de una nueva mathesis. ${ }^{2}$ No obstante, en muchas de sus obras, el pensador francés se presenta a sí mismo como el precursor de una nueva forma de filosofía. A diferencia del saber de los humanistas renacentistas que tenía sus bases en la antigua tradición clásica, él pretendía construir una nueva filosofía sobre bases totalmente nuevas. "Omnia evertenda atque a primis fundamentis denuo inchoandum», afirmará al inicio de sus Meditaciones metafísicas. ${ }^{3}$ El sistema cartesiano será conocido ampliamente como la nueva filosofía, y Descartes el restaurador mismo de este disciplina.

Ciertamente, la novedad del cartesianismo en muchos aspectos representaba una amenaza para las doctrinas escolásticas que se apoyaban en el aristotelismo. Descartes rechazaba las cuatro causas, pues ellas no eran apropiadas para la nueva filosofía natural. Él consideraba impropia la doctrina 
de los cuatro elementos y afirmaba que existía un solo tipo de materia y todas sus variedades podían ser explicadas como modificaciones de la extensión. Además, el autor de las Meditaciones no aceptaba los tres principios básicos de la ontología aristotélica: la materia, la forma y la privación. Excepto para los seres racionales que poseen mentes, él rechazaba así la doctrina de las formas sustanciales (cf. Ariew 1992: 65-66). Del mismo modo, sus críticas contra la silogística, sobre todo en el estado bastante anquilosado que se encontraba entonces, son fundamentales para el desmontaje posterior del edificio lógico de los escolásticos. Otro tanto sucedía con la percepción del cartesianismo en el ámbito teológico. Por más que Descartes insistiese en que sus doctrinas no representaban un amenaza contra la fe, para los jesuitas de entonces, para usar los términos de R. Ariew, toda novedad en el campo teológico o filosófico era percibida como un peligro para el dogma cristiano. ${ }^{4}$

Mencionemos ahora algunas consideraciones acerca del contexto en el que se desarrolla el pensamiento de Descartes. La ciencia tal como se concebía entonces la constituían básicamente las llamadas ciencias teoréticas tales como la metafísica, la física y la teología natural, las cuales eran estudiadas, desde una perspectiva aristotélico-escolástica. A esto se debe añadir una disciplina como la lógica, que cumplía la función de ser, al mismo tiempo, un arte liberal orientado, entre otras cosas, a la elaboración de silogismos y una ciencia que analizaba el modo cómo conocemos las cosas. No obstante, el siglo XVII fue un periodo de intenso cuestionamiento de la eficacia y el valor explicativo de la ciencia aristotélica antes descrita. De ahí la imposibilidad señalada por Clarke de que los profesores de Descartes pudiesen enseñar Aristóteles sin ninguna referencia a los recientes desafíos a su sistema. ${ }^{5}$ Sin embargo, los conceptos básicos con los que Aristóteles pensó el mundo, los tipos de problemas estudiados, así como la óptica a partir de 
la cual se discutieron, continuaron a ser enseñados a los estudiantes de esa época. Fue esta perspectiva general, en lugar de las soluciones detalladas, que Descartes posteriormente desafió con una intensidad que solo podía explicarse por su propia experiencia personal (cf. Clarke 2006: 20).

Un aspecto que no debe ser pasado por alto es el carácter multifacético de los sabios de la época. En muchos personajes de este tiempo, representados ahora solamente como filósofos, podemos encontrar a la vez a hombres de ciencia, matemáticos, físicos, teólogos, juristas, así como sabios preocupados por la aplicación práctica de sus descubrimientos, inventores, o incluso empresarios que producirán nuevos artefactos para uso comercial. Esta multiplicidad de intereses y orientaciones se puede observar en el propio Descartes, quien además de hombre de armas es matemático, físico y filósofo. En suma, en los sabios de ese tiempo la teoría misma se transforma en acción. La propia concepción que se tenía de la filosofía sufrirá entonces un cambio importante. De una concepción de la filosofía como una disciplina teórica orientada a sí misma y sin finalidad práctica alguna ${ }^{6}$ se pasará a concebirla como una forma de saber que tendrá como criterio fundamental la adquisición de un conocimiento práctico por medio de la razón.

No menos radical es la profunda transformación que se opera en el campo de la lógica, transformación en la que Descartes tendrá un papel preponderante. Con él tiene lugar el paso de una concepción discursiva a una concepción facultativa de la inferencia. ${ }^{7}$ El modelo cartesiano de la inferencia es facultativo, pues la deducción para este autor es reducible a la intuición, una facultad anímica. La teoría lógica que desarrolla Descartes sobresale por su coherencia, siendo muy superior a otras teorías que prevalecieron en el siglo XVII (cf. Gaukroger 1989: 3). El adversario que tenía al frente no 
era tanto el genio lógico de Aristóteles, sino representantes relativamente más modestos de esta disciplina. Este hecho ha sido pasado por alto por los comentaristas que han creído que la alternativa a la visión cartesiana era la contenida en el silogismo aristotélico. Pero, en primer lugar, Descartes y sus contemporáneos se refieren a la silogística como un procedimiento para el descubrimiento científico, no como una teoría de patrones de inferencia válida, o como una teoría de lo qué es la inferencia. En segundo lugar, en el nivel de las preguntas filosóficas sobre lo qué es la inferencia, la preocupación se orienta principalmente hacia concepciones escolásticas tardías y ramistas, no tanto hacia la de Aristóteles (Gaukroger 1989:3-4).

Se pueden mencionar otras observaciones acerca de la lógica tal como se practicaba a mediados del siglo XVII. En primer lugar, es esencial ubicar las críticas contra el silogismo en el horizonte más vasto de una discusión acerca de la dialéctica, de la cual la silogística o teoría del razonamiento constituía tan solo una parte. De esta manera, se puede apreciar el verdadero alcance de los argumentos aparentemente simplistas de estos autores acerca de la esterilidad del silogismo (cf. Charrak 2005: 470). A esto se añade que los textos de lógica escolástica de entonces lejos de representar un corpus sin ninguna variación experimentaban profundos cambios en el siglo XVI (cf. Charrak 2005: 469-470). Son estos textos que deben afrontar los restauradores de la filosofía. Por otro lado, no se puede dejar de señalar la aparente unidad que estos críticos confieren a la lógica de Aristóteles al mismo tiempo que la atacan (cf. Charrak 2005: 469).

A pesar de su importancia para comprender el conjunto de la obra de Descartes, así como la construcción del pensamiento lógico moderno, no existían hasta reciente data trabajos que profundicen el análisis cartesiano acerca de la naturaleza de la inferencia, así como las críticas que efectúa este 
autor a la dialéctica escolástica. ${ }^{8}$ En buena parte esto se debe a que Descartes no escribió tratado de lógica alguno, lo que no deja de ser paradojal para un trabajo como el nuestro que pretende estudiar la visión de este autor sobre la materia. Ciertamente, en la década de 1640, después de haber publicado el Discurso y las Meditaciones, él pensó cómo instaurar su propia filosofía en las escuelas a fin de reemplazar a Aristóteles como el nuevo maestro. Para esto, escribió la obra Principia philosophiae con la cual pretendía sustituir los manuales escolásticos, que tenían entonces una forma cuadripartita que representaba la estructura del programa en las escuelas: lógica, física, metafísica y ética. ${ }^{9}$ Pero, su empeño por hacer un curso de filosofía completo tan solo se realizó parcialmente, pues no llegó a escribir manuales de lógica o de ética, fundamentales - sobre todo el primero- para un curso. Solo pudo acabar una física parcial y lo que puede llamarse una metafísica general. ${ }^{10}$ Si bien los Principia no se parecen mucho a los otros manuales de filosofía entonces en uso, se trata con todo de una de las presentaciones más sistemáticas de su filosofía dentro del corpus, y sobre todo de uno de los textos de este autor más conscientemente pedagógicos. Para la traducción al francés, Descartes escribió una introducción que aborda explícitamente la cuestión de cómo se debe aprender filosofía. La idea del método como una especie de ejercicio mental para el entrenamiento del intelecto, anticipación de la lógica concebida como medicina mentis, cumple allí un papel importante. ${ }^{11}$ Después de proveer un código de conducta para regir nuestras acciones mientras estamos reconstruyendo nuestras creencias, él recomienda estudiar la lógica. Pero, como lo sugiere el propio Descartes, la lógica que uno debe tener en cuenta no es propiamente hablando la dialéctica que se enseñaba en las Escuelas (AT IXB 13). 
Nuestro análisis acerca de la concepción cartesiana de la lógica tendrá un doble objetivo. En primer lugar, desde una perspectiva positiva, nos interesa investigar la manera cómo el pensador francés aborda la problemática acerca de la naturaleza de la lógica. Se examinará así la concepción de la inferencia llamada facultativa por diversos autores (cf. Gaukroger 1989: 4), pues involucra diferentes facultades del alma. En esta parte también, se estudiará de manera bastante breve la importancia de este enfoque para interpretar algunos pasajes significativos del pensamiento cartesiano. Después, desde una perspectiva más bien negativa, se analizará las diferentes críticas formuladas por Descartes contra la silogística aristotélicoescolástica. Nos interesa así observar las acusaciones que realiza él contra el silogismo, el cual, además de ser formalmente inválido, pues es una forma de petición de principio o razonamiento circular, no contribuye en nada al descubrimiento científico e incluso puede ser perjudicial para el ejercicio espontáneo de la razón natural.

\section{LA CONCEPCIÓN CARTESIANA DE LA INFERENCIA}

Según Descartes, el proceso de adquirir conocimiento depende de dos acciones centrales del entendimiento: la intuición intelectual y la deducción. Mediante la intuición intelectual se pueden aprehender de forma inmediata, clara y distinta las primeras verdades, mientras que la deducción es la acción intuitiva con la que aprehendemos la conexión entre una serie de verdades. En las Reglas para la dirección del espiritu encontramos el siguiente pasaje que ilustra bien esto (Regla III):

Pero para que en lo sucesivo no caigamos en el mismo error, se enumeran aquí todas las acciones de nuestro entendimiento, por 
las que podemos llegar al conocimiento de las cosas sin temor alguno de error: y tan solo se admiten dos, a saber, la intuición y la deducción [inducción]. ${ }^{12}$

Entiendo por intuición no el testimonio fluctuante de los sentidos, o el juicio falaz de una imaginación que compone mal, sino la concepción (conceptus) de una mente pura y atenta tan fácil y distinta, que en absoluto quede duda alguna sobre aquello que entendemos; o, lo que es lo mismo, la concepción no dudosa de una mente pura y atenta, que nace de la sola luz de la razón y que por ser más simple, es más cierta que la misma deducción, la cual, sin embargo, ya señalamos más arriba que tampoco puede ser mal hecha por el hombre. Así cada uno puede intuir con el espíritu que existe, que piensa, que el triángulo está definido solo por tres líneas, la esfera por una sola superficie, y cosas semejantes que son más numerosas de lo que creen la mayoría, precisamente porque desdeñan para mientes en cosas tan fáciles.

[...] Ahora bien, esta evidencia y certeza de la intuición se requiere no solo para las enunciaciones, sino también para cualquier razonamiento. ${ }^{13}$ (AT X 368-369)

Ambas acciones del entendimiento son aprehensiones directas, por consiguiente la deducción también es intuición, aunque a diferencia de la simple intuición, que trata de aprehender la conexión entre verdades, la deducción opera a un nivel «superior». ${ }^{14}$ La deducción cartesiana puede ser caracterizada tanto por ser primitiva, como por ser evidente. Ambos rasgos están íntimamente ligados entre sí. Que algo es evidente significa, para Descartes, que no puede ser probado, explicado, ni justificado . Esto explica según Gaukroger la insistencia del autor de las Meditaciones sobre la naturaleza primitiva de la inferencia (concebida como una intuición) tiene 
relación con su punto de vista de que las conexiones inferenciales (concebida también como una intuición) son evidentes (cf. 1989: XX).

Como lo señala el propio Descartes, él lleva a cabo un cambio en el contenido semántico de términos como intuición y deducción, de modo que ellos no significan más lo que denotaban para las escuelas. En otro pasaje de esta misma obra (Regla VII), Descartes caracteriza la deducción como la intuición de un todo:

Así pues, si, por ejemplo, he conocido por diversas operaciones mentales, primero, qué relación hay entre las magnitudes $\mathrm{A}$ y $\mathrm{B}$, después entre $\mathrm{B}$ y $\mathrm{C}$, luego entre $\mathrm{C}$ y $\mathrm{D}$, y, finalmente, entre $\mathrm{D}$ y E, no por ello veo qué relación hay entre $\mathrm{A}$ y E, y no puedo comprenderlo precisamente a partir de las ya conocidas, a no ser que las recuerde todas. Por lo tanto, las recorreré varias veces con un movimiento continuo del pensamiento [de la imaginación], ${ }^{15}$ que intuya cada cosa y al mismo tiempo pase a otras, hasta que haya aprendido a pasar tan rápidamente de la primera a la última que, no dejando casi ningún papel a la memoria, parezca que intuyo el todo de una vez, pues de este modo, al mismo tiempo que se ayuda a la memoria, se corrige la lentitud del espíritu y en cierta manera se aumenta su capacidad. (AT X 387-388) ${ }^{16}$

Esto puede ser representado de la siguiente forma:

\begin{tabular}{|c|c|c|}
\hline Prem $^{1}$ & Relación entre magnitudes & $A \& B$ \\
\hline Prem $^{2}$ & ' & $\mathrm{B} \approx \mathrm{C}$ \\
\hline Prem $^{3}$ & “ & $C \& D$ \\
\hline Prem $^{4}$ & ' & $D \circlearrowleft E$ \\
\hline
\end{tabular}


Según esta concepción de la inferencia, al parecer la mente primero intuye cada una de las proposiciones, para después intuir el todo (rem totam en el texto latino), que se podría comprender aquí la totalidad conformada por las premisas $\left(\operatorname{Prem}^{1}, \operatorname{Prem}^{2}, \ldots, \operatorname{Prem}^{n}\right)$ y la conclusión. Así, lo que la luz de la razón hace en primera instancia es permitirnos comprender la relación entre ideas de forma clara y distinta. Pero, en algunas ocasiones tenemos que conectar esas ideas por medio de inferencias. Por consiguiente, se requiere hacer uso en esos casos de la intuición totalizante o deducción. En el ejemplo mencionado por Descartes, el todo intuido sería equivalente así a la presentación ante el espíritu puro y atento de la relación entre las cuatro premisas y la conclusión, mientras que la intuición totalizante puede entenderse como la aprehensión de las conexiones de una relación de tipo inferencial.

En la Regla IV, Descartes señala que nada puede superar a la luz natural de la razón, en clara referencia a la deducción concebida como un intuitus. En este pasaje también se recalca la inutilidad de otras operaciones que para los escolásticos podrían venir al auxilio de la deducción. Puesto que para él la intuición intelectual es una facultad natural, no existen entonces reglas abstractas o patrones de inferencia que gobiernan la intuición totalizante o deducción: «En cuanto a las otras operaciones de la mente que la Dialéctica intenta dirigir con la ayuda de estas primeras, son aquí inútiles, o más bien, deben ser contadas entre los obstáculos, pues nada puede añadirse a la pura luz de la razón que de algún modo no la oscurezca» ${ }^{17}$ (AT X 372-373).

Incluso los preceptos cartesianos como las cuatro reglas del método, permiten tanto solo o bien un mejor uso de esta facultad, o bien el no caer en el error cuando se indaga la verdad en las ciencias humanas. ${ }^{18} \mathrm{La}$ 
deducción por consiguiente no es percibida como un proceso inferencias gobernado por reglas lógicas, sino como el ejercicio de la facultad intelectual basado en la intuición. La idea de grados de probabilidad es totalmente ajena a la concepción intuicionista de la lógica. Esta luz de la razón, o luz de la naturaleza, como se le llama también en la Regla 10, al parecer, no puede inducirnos al error, ya que «ninguno de los errores que los hombres cometen se deben a la inferencia errónea, sino que son causados por el mero hecho de que se basan en experiencias mal comprendidas, o porque las proposiciones apresuradas o sin fundamento se presentan» (AT X 365).

De este modo, la deducción no se concibe en términos de un proceso discursivo sino que es algo que no puede ser analizado o explicado. Es una operación mental por la cual se capta conexiones entre ideas. Gaukroger resume bien esto: «Comprender una inferencia no consiste en la explicación y el análisis detallados de cada uno de sus pasos, sino en tratar de evitar estos pasos, de manera que uno puede comprender la conexión que exhiben por sí mismos, libre de la mediación de los pasos lógicos, por así decirlo» (1989:128). ${ }^{19}$ Tal como Descartes la concibe, la deducción siempre es una inferencia inmediata. Uno, no obstante, podría preguntarse si es posible justificar esta inferencia. Para el pensador francés, tal justificación se orientaría a buscar pruebas para convencerse uno mismo, más que para convencer a un oponente, como sucedía en la dialéctica medieval. Pero, en sí misma, esta pretensión de justificación resulta imposible, pues como lo señala Gaukroger la comprensión de una inferencia como un intuitus es la comprensión más primitiva y fundamental que tenemos (1989: 127-130). 


\section{LA LÓGICA FACULTATIVA Y LAS CRÍTICAS AL SILOGISMO}

El silogismo, que había sido el elemento central de la lógica desde la Antigüedad hasta finales de la Edad Media, fue objeto de una creciente oposición desde mediados del siglo XVI. A las críticas que desarrollan los humanistas del Renacimiento, se añaden las decisivas de Bacon y Descartes. Los argumentos contra el empleo del silogismo que aparecen en los textos de estos dos autores fueron retomados prácticamente por todos los filósofos posteriores: desde Arnauld y Locke hasta los teóricos del inductivismo de la primera mitad del siglo XIX, con los que se terminó por desmontar casi por completo el edificio lógico construido por los escolásticos.

En esta parte de nuestro trabajo, vamos examinar tres de las críticas que Descartes formula contra el silogismo: la afirmación de que el silogismo es inválido formalmente, la afirmación de que no produce nuevas verdades, y la afirmación de que su práctica es perjudicial para la razón natural. Las dos primeras objeciones están íntimamente ligadas entre sí, pues ambas a presuponen de diferente forma que el silogismo es un razonamiento circular. En el primer caso, se establece esto formalmente, en el segundo se determinan las consecuencias prácticas que tiene en la ciencia el empleo de este razonamiento circular. La última aseveración, el supuesto carácter nocivo del silogismo para la razón, tiene relación más bien con la concepción cartesiana de la inferencia como intuición.

Es necesario mencionar dos observaciones generales antes de pasar a examinar los diferentes aspectos de la crítica cartesiana al silogismo. En primer lugar, las objeciones a la silogística se desarrollan al mismo tiempo que se formulan una serie de interrogantes acerca de la naturaleza de la inferencia deductiva y del descubrimiento científico por parte de pensadores como Bacon y Descartes. Incluso se puede establecer una cierta relación 
causal entre estas tres cuestiones. Si se rechaza el silogismo por ser un instrumento ineficaz para la invención, se opta entonces por una concepción diferente del descubrimiento científico, que a priori es más eficaz que la herramienta empleada por los escolásticos. Pero, esto lleva a replantear lo que es la inferencia que constituye algo así como el esqueleto metodológico del descubrimiento, por ejemplo, si puede al mismo tiempo preservar la verdad y ampliar nuestro conocimiento. En segundo lugar, la relación entre estas cuestiones no ha sido analizada con claridad hasta reciente data. En parte esto se debe a que Descartes y Bacon no desarrollaron detalladamente sus argumentos contra el silogismo. Muchas veces, bastaba con señalar simplemente que el silogismo era falaz e inútil para la Nueva ciencia para descartarlo en lo sucesivo (cf. Gaukroger 1989: 6).

A estas observaciones generales, se debe añadir que en el caso de Descartes existía una especie de autocensura o incluso de prudencia práctica que le impedía expresar abiertamente su rechazo a la filosofía escolástica. Esta es la principal causa, creemos nosotros, que las posiciones de este autor en cuanto a la silogística puedan parecer muchas veces fluctuantes, incluso contradictorias. Como sucedió con su decisión de no publicar su Tratado acerca del mundo debido a las consecuencias que podía acarrearle, el pensador francés silenció su rechazo a la lógica formal, al igual que tuvo que bajar el tono de su oposición a otros aspectos de la doctrina escolástica. Ejemplo de esto son sus respuestas plenas de retórica y de metáforas a la Séptima serie de objeciones a las Meditaciones del jesuita Pierre Bourdin (AT VII 522, 544). En ese momento él pretendía que los jesuitas, sus antiguos maestros, estuviesen de su lado para imponer su filosofía en las escuelas que en buena parte eran controladas por la Compañía de Jesús, y por eso hacía todo lo posible para no ofenderlos (cf. Garber 2000: 287). ${ }^{20}$ 


\subsection{EL SILOGISMO ES UN RAZONAMIENTO CIRCULAR}

La principal objeción contra la lógica escolástica se centró en la supuesta falacia en la que cae el silogismo: el razonamiento circular o petición de principio. ${ }^{21}$ De manera general, el término petición de principio (o petitio principii) se utiliza en la actualidad para indicar cualquier argumento falaz donde la verdad de la conclusión está ya implícita en una o más de las premisas (cf. Cook 2009: 31). Más específicamente, se trata de una falacia informal que se produce cuando el que razona presenta un argumento a favor de una conclusión, pero omite una premisa fundamental, cuya aceptación implicaría la previa aceptación de la conclusión. En el caso de la crítica cartesiana al silogismo, la petición de principio podría presentar la siguiente forma:

Las premisas de un silogismo no pueden establecer la conclusión (o pregunta), en cuanto que es necesario saber antes que la conclusión es verdadera para poder hacer uso de una o ambas premisas que conforman este argumento. Por consiguiente, se puede concluir que el silogismo es falaz.

Una consecuencia de la petición de principio señalada en esta caracterización es que el descubrimiento de algo nuevo no puede depender del silogismo, pues la verdad de las premisas con las que se pretende establecer la exactitud de la conclusión, depende de nuestro conocimiento previo de la verdad de la conclusión. Formulada de esta manera, no es difícil comprender la circularidad que afecta al silogismo, al menos el demostrativo, no obstante como lo dejamos entrever líneas atrás Descartes no desarrolla su crítica con la claridad y extensión deseadas. 
Consideremos, antes de proseguir con nuestro análisis, dos definiciones importantes relativas a la demostración y al silogismo, las cuales aparecen en el Órganon. Aunque Aristóteles no proporciona definición alguna de silogismo, ${ }^{22}$ se puede establecer por los ejemplos mencionados en los Analíticos primeros (I 4-22) la siguiente enunciación: ${ }^{23}$

Silogismo ${ }^{1}=(\mathrm{df})$ argumento que contiene dos premisas y una conclusión, siendo cada una de estas proposiciones una proposición categórica, y poseyendo un total de tres términos, uno de los cuales (llamado término medio) está presente en cada premisa, pero no en la conclusión.

Aristóteles analiza, a su vez, la noción de demostración en los primeros seis capítulos de los Analíticos segundos. Una demostración es una especie de deducción o syllogismos tis, en virtud de la cual "poseemos conocimiento» (An. pr. I 4, 25b 30). ${ }^{24}$ La deducción demostrativa podría ser definida de la siguiente forma (es necesario emplear una definición recursiva): ${ }^{25}$

Deducción o silogismo demostrativo $^{1}=(\mathrm{df})$

(1) $\left(\left\{\mathrm{a}_{1}, \mathrm{a}_{2}, \ldots, \mathrm{a}_{\mathrm{n}}\right\}, \sigma\right)$ es una demonstración de $\sigma$ si

(i) $\left(\left\{a_{1}, a_{2}, \ldots, a_{n}\right\}, \sigma\right)$ es una deducción; $y$

(ii) cada a es una premisa probatoria para $\sigma$

(2) a es una premisa probatoria de $\sigma$ si

(i) a es un principio de $\sigma$, ó 
(ii) hay una deducción $\left(\left\{b_{1}, b_{2}, \ldots, b_{n}\right\}, a\right)$, tal que cada $b$ es una premisa probatoria de $\sigma$.

(3) a es un principio de $\sigma$ si

(i) a es verdadero, universal, necesario, primero, inmediato, conveniente, anterior a la conclusión, más familiar que y causa de la conclusión.

Donde, $\alpha$ es una premisa de la demostración y $\sigma$ indica la conclusión. Es importante recalcar que las premisas deben ser principios (2.i) ó provenir de una deducción (2.ii). Una premisa demostrativa es principio solamente si cumple ciertas condiciones según los Analíticos segundos. De este modo, las premisas son principios demostrativos si son verdaderas, universales, necesarias, primitivas o primeras, inmediatas, convenientes, anteriores a la conclusión, más familiares que y causas de ella (An. Post. I 2 y I 4). Una proposición que cumpla estos nueve requisitos es un principio o arché de la conclusión.

No obstante, si se repasa la forma en que los lógicos escolásticos y los tradicionales interpretaron el silogismo demostrativo propuesto por Aristóteles, se tendría que mencionar una versión diferente de mismo, en la cual en vez de hablar de deducción en la definición mencionada arriba (ver en 2.ii) se hablaría más bien de silogismo, entendido este término como un argumento de dos premisas o proposiciones categóricas.

La definición de principio también podría variar de acuerdo a la interpretación dada por un autor determinado. Así, se puede definir la demostración también de este modo: 
Silogismo demostrativo ${ }^{2}=(\mathrm{df})$

(1) $\left(\left\{\mathrm{a}_{1} \& \mathrm{a}_{2}\right\}, \sigma\right)$ es una demonstración de $\sigma$ si

(i) $\left(\left\{\mathrm{a}_{1} \& \mathrm{a}_{2}\right\}, \sigma\right)$ es un silogismo ${ }^{1}$; $y$

(ii) cada a es una premisa probatoria para $\sigma$

(2) a es una premisa probatoria de $\sigma$ si

(i) a es un principio de $\sigma$.

(3) a es un principio de $\sigma$ si

(i) a puede presentar alguna de las nueve características mencionadas en la definición del silogismo demostrativo ${ }^{1}$.

Como señalamos anteriormente, la crítica del silogismo como petición de principio aparece en la regla x de las Regulae de una manera no del todo clara:

Pero para que aparezca todavía con más evidencia que aquel arte de razonar en nada contribuye al conocimiento de la verdad, es preciso señalar que los dialécticos no pueden formar con su arte ningún silogismo que concluya en la verdad, a menos que posean antes la materia del mismo, esto es, si no conocieran ya antes la misma verdad, que deducen en el silogismo. ${ }^{26}$ (AT X 406) ${ }^{27}$

La crítica se repite al inicio de la regla XIII, donde el pensador francés afirma lo siguiente acerca de los dialécticos o lógicos escolásticos: 
Imitamos a los Dialécticos en esto solo, en que así como ellos, en la enseñanza de su doctrina de las formas del silogismo, suponen que los términos o el contenido de sus silogismos son ya conocidos, así también nosotros exigimos aquí que la cuestión sea perfectamente entendida. ${ }^{28}$ (AT X 430)

Después de formular estas críticas, Descartes se orienta a la observación de que los silogismos no pueden conducir a nuevas verdades. Pero es importante que consideremos que se tratan de dos cuestiones distintas: la relación entre las premisas y la conclusión del silogismo, y si con el silogismo se produce un incremento de nuestro conocimiento.

Aunque Descartes no desarrolla in extenso su crítica al silogismo como razonamiento circular, se puede inferir que tiene en mente la formulación clásica de la misma. ${ }^{29}$ Se puede distinguir dos tratamientos usuales en las críticas del silogismo procedentes de la Antigüedad. ${ }^{30} \mathrm{El}$ primero es un argumento escéptico que niega la existencia del silogismo como prueba. La base de este argumento es la negación de que los condicionales sean inferencias. Ahora bien, si el silogismo es un tipo de condicional, no puede ser entonces una inferencia. El segundo argumento se centra en que en los silogismos el tipo de evidencia que se necesitaría para apoyar una de las premisas es precisamente la proporcionada por la conclusión. Esto hace que el argumento sea circular. Esta objeción es legítima en el caso del silogismo demostrativo. Nosotros vamos a desarrollar únicamente el segundo argumento clásico contra el silogismo. ${ }^{31}$

El silogismo es un caso de argumento circular o dialelo. La palabra griega diallêlos suele traducirse en español por círculo vicioso o razonamiento circular. ${ }^{32}$ Es uno de los cinco modos de suspensión del asentimiento formulados por Agripa, los cuales son mencionados por Sexto Empírico en 
sus Esbozos pirronianos. ${ }^{33}$ Sexto lo define de la siguiente forma: «El modo del dialelo ocurre cuando lo que sirve para asegurar la cosa sobre la cual trata la investigación necesita de esta cosa para confirmar la convicción, entonces no siendo capaces de tomar una para establecer la otra, suspendemos nuestro asentimiento sobre ambas» ${ }^{34}$ (PH I, 169). Diógenes Laercio lo define del mismo modo y añade un ejemplo ilustrativo del mismo: «por ejemplo, si se desea establecer firmemente la existencia de poros a partir de la producción de emanaciones, y si se emplea esto [la existencia de poros invisibles] para establecer la producción misma de emanaciones» (Vitae, IX 89). ${ }^{35}$

El dialelo en un sentido más amplio, es decir considerado como modo de suspensión no puede operar solo, sino que como los otros modos propuestos por Agripa no puede superarse sin caer en otro modo. En el caso del razonamiento circular, este tiene una propensión natural a caer en el modo de la regresión al infinito, siendo difícil de distinguir un modo del otro. ${ }^{36}$ En su ataque contra la lógica aristotélica, Sexto considera el siguiente ejemplo de silogismo para ilustrar la circularidad: "Sócrates es un hombre, ningún hombre es cuadrúpedo, por tanto Sócrates no es cuadrúpedo», a continuación comenta lo siguiente:

Quieren confirmar la premisa «ningún hombre es cuadrúpedo» por inducción a partir de elementos particulares, deseando así deducir cada una de las proposiciones particulares de «ningún hombre es cuadrúpedo». Por lo tanto caen en la confusión del dialelo. (PH II 197)

Así, los silogismos de este tipo no pueden ni proveer pruebas ni establecer la verdad de la conclusión, pues proceden de lo universal a lo particular, pero al mismo tiempo también deben recurrir a argumentos que 
proceden de lo particular a lo universal. Este pasaje en Sexto es el origen de la célebre acusación de que los silogismos «asumen o toman la cosa por cierta» o en términos más cartesianos «a menos que posean antes la materia del mismo» si se usan como evidencia. Si se considera el ejemplo de silogismo mencionado líneas atrás, no se puede establecer la conclusión de que «Sócrates no es un cuadrúpedo», en cuanto que se debe saber antes que «Sócrates no es cuadrúpedo» para poder hacer uso de la premisa de que «ningún hombre es cuadrúpedo» (Barnes 1995:91-92).

Una posible objeción a la explicación que hemos desarrollado acerca del rechazo de Descartes a la escolástica aristotélica es la propuesta por John G. Cottingham (1995: 19-20). Para él, más que una objeción a la estructura formal del silogismo, esto es a su validez lógica, lo que el pensador francés rechazaba es la manera en que los escolásticos hacían uso de la lógica aristotélica. Cottingham se basa en que el autor de las Meditaciones no tenía reparos al silogismo en cuanto tal: «yo mismo siempre he estado preparado para usar silogismos cuando la ocasión lo requiriera» (AT VII 522). ${ }^{37}$ De este modo, la oposición de Descartes a la silogística se basaría fundamentalmente en la pertinencia de su utilización en ciertos contextos argumentativos o incluso en su uso puramente mecánico. Un análisis del empleo que da el filósofo francés al término dialéctica muestra según este intérprete que los argumentos en esta disciplina no son necesariamente erróneos, si no que muchas veces son «argumentos de cajón», que se empleaban más por un afán de vencer en un debate que para incrementar nuestro conocimiento o para la búsqueda de la verdad. La dialéctica se transformó así en un simple juego que para ganarlo dependía sobre todo de la habilidad en la manipulación de cierta terminología y reglas (cf. Cottingham 1995: 20). 
Si bien se puede aceptar buena parte de lo que expresa este autor acerca de la actitud de Descartes frente a la dialéctica, sin embargo no creemos que su rechazo a la misma se reduzca a un problema en cuanto al uso del silogismo por parte de los lógicos de las escuelas. En realidad, esta interpretación no recoge la diferencia sustancial que existe entre dos concepciones diametralmente opuestas de la inferencia: la facultativa que hemos desarrollado aquí y la discursiva, en la cual se asiente el sistema lógico de Aristóteles y de los escolásticos. No se trata, creemos, de un problema de aplicación de la silogística, sino de dos visiones distintas de la inferencia y, por consiguiente, de la lógica. Además, la afirmación mencionada en AT VII 522 puede entenderse por el contexto en el que se inserta ${ }^{38}$ como un intento por parte del pensador francés de mostrar la continuidad de su pensamiento con el de sus antecesores o incluso como una autocensura que le impedía expresar abiertamente su opinión acerca de la lógica escolástica.

Como veremos en la siguiente parte de nuestro estudio de la lógica cartesiana, el problema se complica aún más por el hecho de que las formas de argumentación diseñadas originalmente para sistematizar los resultados de lo que se había encontrado como era el caso del silogismo apodíctico de Aristóteles fueron consideradas por los lógicos tradicionales como formas de argumentación elaboradas para obtener resultados en el contexto de la llamada Lógica del descubrimiento.

\subsection{El SILOGISMO NO TIENE NINGÚN PAPEL HEURÍSTICO, POR CONSIGUIENTE NINGUNA UTILIDAD}

El estudio de la lógica en el siglo XVI abarcaba no solo las formas válidas de inferencia deductiva, sino también lo que puede llamarse la lógica del descubrimiento. ${ }^{39}$ En esta concepción amplia de la lógica, Descartes ocupa 
un lugar preponderante. No debe causar sorpresa entonces que para muchos de sus contemporáneos Descartes en cuanto a su visión del método científico era percibido como bastante próximo al pensador inglés, Francis Bacon, tal como lo atestigua una célebre carta de la princesa Elizabeth al pensador francés fechada el 21 de febrero de $1647 . .^{40}$ Esta aproximación se explica en parte debido al cuestionamiento que realizan ambos autores, aunque con perspectivas ciertamente diferentes, al sistema aristotélico todavía imperante. Pero, sobre todo a que igual que Bacon él fue considerado en el siglo XVII como el gran defensor del método hipotético.

Esta visión difiere con la representación predominante de este autor en el siglo Xx, según la cual, de alguna manera, todo el conocimiento científico se deduce del cogito. ${ }^{41} \mathrm{El}$ Novum organum y las Regulae resaltan así la esterilidad de lógica escolástica para la filosofía natural, al ser silogismo poco compatible con las condiciones de la invención (cf. Charrak 2005: 473), para proponer por vías distintas un método científico que pretende ampliar nuestro conocimiento.

Un elemento clave para comprender por qué Descartes fue considerado en su tiempo un partidario del método hipotético es que a diferencia de lo que sucede en nuestros días la lógica deductiva y la lógica del descubrimiento no estaban separadas. En nuestros días, este punto de vista puede parecer contradictorio, pues la deducción es concebida como un procedimiento que ante todo preserva la verdad, pero no permite incrementar nuestro conocimiento. El siguiente pasaje, extraído de un texto de Emily Grosholz, ilustra bien esto: ${ }^{42}$

Por otra parte en la medida en que Descartes cree que su método a la vez amplia el conocimiento y preserva la verdad, no puede ser aplicado con éxito, pues, como tal, es inexistente. Los métodos 
inductivos que extienden el conocimiento son corregibles, y los métodos deductivos que transmiten fiablemente la verdad no pueden ser ampliativos. (1991: 8)

Grozholz tendría razón si la concepción cartesiana de deducción fuese idéntica a su contraparte contemporánea. Hemos visto no obstante que esto no es el caso. De este modo, la deducción o intuición totalizante tal como la concibe este filósofo puede ser representada también como un medio para el descubrimiento de nuevas verdades. Sin embargo, no tener en cuenta las razones y el modo cómo se produce esta relación que es para mucho de nuestros contemporáneos desconcertante dificultaría establecer límites entre ambas posteriormente.

En la regla $\mathrm{x}$ de las Regulae, inmediatamente después de afirmar que los silogismos necesitan haber comprobado antes la verdad de lo que pretenden deducir, Descartes manifiesta su rechazo de que con el silogismo podamos conocer algo nuevo:

De donde resulta evidente que ellos mismos no aprenden nada nuevo a partir de tal forma [del silogismo], y que por ello la Dialéctica tal como se entiende comúnmente es totalmente inútil para los que desean investigar la verdad de las cosas, y que tan solo puede servir a veces para exponer a otros más fácilmente las razones ya conocidas, por lo que debe ser transferida de la Filosofía a la Retórica. ${ }^{43}$ (AT X 406)

La dialéctica tal como se concebía en la época de Descartes era ineficaz si se trataba de explorar los diferentes aspectos de la realidad, teniendo a lo sumo un valor expositivo. De este modo, más que formar parte de la 
filosofía o incluso ser un instrumento de esta disciplina, la dialéctica debía ser incluida dentro de la retórica, tal como era entendida esta disciplina por los Renacentistas.

\section{OBSERVACIONES FINALES}

En resumen, el silogismo no puede ser un instrumento de descubrimiento, en el sentido de que la conclusión pueda decirnos algo objetivamente nuevo. Si Descartes tal como lo señalamos antes silenció su rechazo a la lógica de las escuelas, es claro a pesar de esto que él no consideraba la silogística como formando parte de la ciencia y de la enseñanza. A pesar de su "política de templanza», él llegará a sostener algunas veces que la silogística que se enseñaba en las escuelas no presenta valor alguno, pues «la mayoría de sus técnicas son de menos utilidad para aprender cosas que para explicar a otros las cosas que uno ya conoce» (AT VI, 17). A diferencia de su método, al cual a veces él se refiere como la lógica verdadera, la lógica escolástica no puede ayudarnos a encontrar nuevas verdades, tan solo sirve para ordenar aquellas verdades que ya hemos descubierto por algún otro medio.

Lo que los modernos critican —en realidad — es una pálida sombra de lo que quiso sugerir Aristóteles por demostración. Como lo señalan un buen número de autores, los equívocos comienzan por la propia interpretación de lo que es silogismo aristotélico. ${ }^{44}$ Así, no es de extrañar que en el siglo XVII la silogística fuese mal entendida en muchos aspectos, tanto por sus detractores como por su número cada vez menor de defensores. A esto se añade que los cargos de circularidad formulados contra el silogismo demostrativo dependían en gran medida de que este fuese considerado como un instrumento de descubrimiento, algo que en realidad Aristóteles nunca pretendió. 
Para comprender esto último, es necesario intentar reconstruir la finalidad que tenía el silogismo demostrativo para Aristóteles. La interpretación tradicional del papel de la demostración en las ciencias era que el campo de aplicación del silogismo apodíctico no era la totalidad de las ciencias, sino solamente las ciencias matemáticas de aquel entonces como la aritmética, la geometría, la estereometría, la mecánica, y la armónica que eran por decirlo así las únicas candidatas posibles para que se aplique el método demostrativo, tal como lo concebía el filósofo griego. A diferencia de otras ciencias menos estrictas como la física o la biología, las matemáticas cumplían a la perfección los requisitos mencionados páginas atrás de que la deducción demostrativa debe estar compuesta de premisas o principios que son verdaderas, necesarias, y universales. ${ }^{45}$ No obstante, si se realiza una lectura más profunda del contexto en el cual se desarrolla la teoría aristotélica de la demostración se puede ver que las matemáticas no se asociaban tan estrechamente con ésta, como se suponía anteriormente. ${ }^{46}$

En realidad, el silogismo demostrativo no fue diseñado como una herramienta de investigación, sino como un instrumento puramente expositivo y didáctico. Para Aristóteles, la demostración era ante todo un dispositivo pedagógico que proporcionaba una explicación de una conclusión que se conocía de antemano. El procedimiento para la obtención de tales conclusiones no era proporcionado por el silogismo apodíctico, sino por otros métodos, entre los cuales cabe señalar los tópicos. Su preocupación entonces era simplemente la presentación formal y sistemática. Aristóteles consideraba que el papel principal de los tópicos era proporcionar estrategias para la clasificación o caracterización de los problemas, de manera que puedan ser resueltos, o descubiertos si empleamos una terminología más reciente, utilizando el conjunto de argumentos, técnicas o disputas que 
inicialmente se desarrollaron en el contexto de la argumentación dialéctica. Pero como el pensador griego muestra un interés cada vez más creciente por las propiedades formales de los argumentos y por la demostración científica, los tópicos se complementaron con una descripción formal de la estructura de los argumentos: los silogismos (Gaukroger 1989: 31). Esto fue demostrado definitivamente hace más de cuarenta años por Jonathan Barnes. ${ }^{47}$

\section{NOTAS}

1. AT IV, 141. "Je sais qu'on a crû que mes opinions étaient nouvelles; \& toutesfois, on verra icy que je ne me sers d'aucun principe, qui n'ait été receu par Aristote, \& par tous ceux qui se font jamais meslez de philosopher» (París, octubre 1644). Para las citas de los textos del filósofo francés utilizamos la edición de referencia, Oeuvres de Descartes, rev. ed. de C. Adam y P. Tannery, Paris: Vrin y CNRS,1964-76 (en adelante abreviado como AT). Hemos modernizado parcialmente el texto en francés o en latín de la edición de AT.

2. Nos referimos a las Reglas para la dirección del espiritu, obra escrita hacia 1628-1629. En latín, "primi Philosophiae inventores» (AT X 375).

3. 'debemos demoler todo por completo y empezar de nuevo desde los cimientos' (AT VII 17). La revolución iniciada por Descartes se expresa incluso en su forma de escribir filosofía. Como bien lo afirma Cottingham, el radicalismo de su pensamiento es inmediatamente evidente, incluso desde el punto de vista del estilo, contrastando con autores anteriores como Montaigne. Al contrario del escudo protector de citas y alusiones literarias con el que tantos escritores de finales del siglo XVI e inicios del XVII rodeaban sus escritos, el estilo de escritura de Descartes es en extremo magro y sin adornos (2008: 54).

4. A diferencia del jansenismo, el cartesianismo no se definía desde el principio en términos de proposiciones que la iglesia proclamaba explícitamente como heréticas (Orcibal 1953: 47). No obstante, después del fallecimiento de su fundador en 1650, el cartesianismo, sobre todo en tanto filosofía natural, se vio envuelto en controversias teológicas relacionadas principalmente con la eucaristía. Es por esto que sus escritos fueron ubicados en el célebre Index librorum prohibitorum de 1663. La prohibición estuvo precedida por la condenación por parte de la Facultad de Teología de 


\section{DESCARTES Y LOS INICIOS DE LA LÓGICA FACULTATIVA}

Lovaina de cinco proposiciones de Descartes, tres de las cuales correspondían a la eucaristía. Por ejemplo, a partir de las tesis cartesianas se podía deducir que la materia corpórea del pan eucarístico está unido al espíritu a diferencia de lo propuesto en el Concilio de Trento, donde se afirmaba que el cuerpo de Cristo está presente «real y sustancialmente» en la eucaristía. Sobre este punto, ver la correspondencia de 1645 con el jesuita Mesland. Esta aparente consecuencia teológica de algunas tesis del pensador francés paradójicamente lo hacía cercano a la interpretación calvinista de la eucaristía, según la cual Cristo está presente solo espiritualmente en este sacramento (cf. Orcibal 1953: 39-53).

5. Este autor se refiere a los desafíos planteados por la Nueva ciencia a la física aristotélica, a lo que nosotros podemos añadir también al sistema lógico peripatético.

6. Se trata del paradigma aristotélico de la ciencia tal como es expuesto en la Metafísica (Met. I, 2 982a 30-32). Existían ciertamente otras concepciones acerca de la filosofía en la Antigüedad. Por ejemplo, a partir del helenismo usualmente se consideraba la filosofía en tanto un determinado modo de vida.

7. Para usar los términos de Gaukroger (1989: 3-4), que a su vez toma prestada esta expresión de G. Buickerood. Este último autor emplea el término «facultativo» en su texto The Natural History of the Understanding: Locke and the Rise of Facultative Logic in the Eighteenth Century, History and Philosophy of Logic, 6 (1985), pp. 157-190. Buickerood, no obstante, parece considerar la lógica facultativa como un fenómeno postcartesiano, mientras que para Gaukroger se inicia precisamente en el siglo XVI con Descartes.

8. Decimos «hasta reciente data", pues en 1989 se publicó un trabajo remarcable que llenó en buena parte este vacío en los estudios cartesianos. Nos referimos a Cartesian logic de Stephen Gaukroger. En él, su autor intenta reconstruir la lógica cartesiana, a través de un profundo análisis de la naturaleza de la inferencia deductiva en su contexto histórico y su relación con el método, cf. Gaukroger S. (1989). Cartesian Logic. Oxford University Press. Aunque mucho menos específico que el texto de Gaukroger, la monumental obra de W. Risse, Die Logik der Neuzeit (La lógica de los tiempos modernos), publicada entre 1964 (primer volumen) y 1970 (segundo volumen), representó también un avance muy importante en la comprensión de la lógica cartesiana.

9. Sobre la concepción de los Principios como libro de texto para las escuelas, véase la carta de Descartes a Mersenne, 31 de diciembre de 1640 (AT III 276). Los Principios de la filosofía fueron publicados por primera vez en Ámsterdam en 1644. La primera edición en francés data de 1647.

10. Nos referimos -claro está- a los Principia, en los que retoma temas de las Meditaciones Metafísicas (primera y segunda parte), y el tratado Acerca del mundo, que fue publicado póstumamente. Sobre este punto, ver el artículo de Ariew R. 


\section{RAFAEL CERPA ESTREMADOYRO}

(2006). Descartes, les premiers cartésiens et la logiqu. Entre las tentativas posteriores para escribir una física de corte cartesiano encontramos las Adiciones al Tratado del hombre de Louis de la Forge. En el caso de la redacción de un manual de metafísica un poco más convencional que las Meditaciones tenemos la Ontosophia de Clauberg. Respecto a una ética cartesiana, se dispone de un tratado anónimo escrito en latín y compuesto de tres partes, que fue elaborado utilizando las expresiones del propio Descartes sobre este tema. Sobre este punto, ver ARIEW 2006: 56.

11. Sobre este punto ver el texto de GARBER 2000: 285.

12. El pasaje señalado tiene un problema de orden textual. En la primera edición de las Regulae, aparece el término "inductio» ('inducción'). Sin embargo, si se conserva «inducción» (inductio), en vez de remplazarla por «deductio» ('deducción'), se haría énfasis, como señala G. Rodis-Lewis (L'oeuvre de Descartes, Lib. Philosophique J. Vrin, París, 1971, Vol. I, p. 171), en la analogía con la inferencia o illatio, término que expresa, como señala J. L. Marión, «la reducción de la exterioridad de la deducción a la presencia del intuitus», y por ella «el dominio del discurso se reduce al intuitus». Seguimos tanto la edición de A.T. como la de J. L. Marión y la del traductor de esta obra al castellano, Juan Manuel Navarro Cordón. Las referencias al texto de RodisLewis y al de J. L. Marión han sido señaladas por este último (1996: 75).

13. "Sed ne deinceps in eumdem errorem delabamur, hîc recensentur omnes intellectûs nostri actiones, per quas ad rerum cognitionem absque vllo deceptionis metu possimus pervenire: admittunturque tantùm duae, intuitus scilicet \& deduction [inductio].

Per intuitum intelligo, non fluctuantem sensuum fidem, vel malè componentis imaginationis judicium fallax; sed mentis purae \& attentae tam facilem distinctumque conceptum, vt de eo, quod intelligimus, nulla prorsus dubitatio relinquatur; seu, quod idem est, mentis purae \& attentae non dubium conceptum, qui à solâ rationis luce nascitur, \& ipsâmet deductione certior est, quia simplicior, quam tamen etiam ab homine malè fieri non posse suprà notavimus. Ita vnusquisque animo potest intueri, se existere, se cogitare, triangulum terminari tribus lineis tantùm, globum vnicâ superficie, \& similia, quae longé plura sunt quàm plerique animadvertunt, quoniam ad tam facilia mentem convertere dedignantur».

14. Para diferenciar ambas se empleará en lo sucesivo intuición simple (o intuición sin más) para la aprehensión directa de las verdades, mientras que la intuición totalizante (o deducción) designará la aprehensión de la conexión entre una serie de verdades. Decimos «ambas acciones», donde se puede entender como una sola acción del entendimiento, la aprehensión directa, no mediatizada, operando a niveles diferentes.

15. En el pasaje mencionado existe una dificultad textual. El lectura que siguen Adam y Tannery, es la de los manuscritos A y $\mathrm{H}$, que dice textualmente: "Con un movimiento de la imaginación» ('imaginationis motu'). Al igual que Crapulli, Marion y el traductor al castellano de las Regulae, Juan Manuel Navarro Cordón, nos parece 


\section{DESCARTES Y LOS INICIOS DE LA LÓGICA FACULTATIVA}

preferible leer "con un movimiento del pensamiento" ('cogitationis motu'), pues además del contexto se evita así la poca pertinencia de incluir a la imaginación en la deducción, entendida esta última como intuición seriada, habiendo sido descartada desde la intuición el papel de la imaginación.

16. «Si igitur, ex. gr., per diversas operationes cognoverim primo, qualis sit habitudo inter magnitudines $A \& B$, deinde inter $B \& C$, tum inter $G \& D$, ac denique inter $D \& E$ : non idcirco video qualis sit inter $A \& E$, nec possum intelligere praecisè ex jam cognitis, nisi omnium recorder. Quamobrem illas continuo quodam imaginationis [cogitationis: Crapulli et Marion] motu singula intuentis simul \& ad alla transeuntis aliquoties percurram, donec à prima ad vltimam tam celeriter transire didicerim, vt ferè nullas mémorise partes relinquendo, rem totam simul videar intueri; hoc enim pacto, dum mémorise subvenitur, ingenij etiam tarditas emendatur, ejusque capacitas quâdam ratione extenditur».

17. "Aliae autem mentis operationes, quas harum priorum auxilio dirigere contendit Dialectica, hic sunt inutiles, uel potius inter impedimenta numerandae, quia nibil puro rationis lumini superaddi potest, quod illud aliquo modo non obscuret».

18. Sobre este último punto, ver la Lógica de Port-Royal IV, 2.

19. "Understanding an inference consists, not in spelling out and analysing its steps, but in trying to bypass these steps altogether so that one can grasp the connection they exhibit in its own right, free from the mediation of logical steps, as it were» (Gaukroger 1989: 128).

20. Se trataba de que las escuelas administradas por los jesuitas asumiesen como texto los Principia philosophiae de 1644. La Séptima serie de objeciones apareció en la segunda edición de las Meditaciones (1647). Como lo señala Garber, este no fue un incidente aislado. Al escribir a su entonces discípulo Henricus Regius en enero de 1642, Descartes explicó su política general de temple sus puntos de vista en situaciones delicadas para no causar hostilidad innecesaria; ver (AT III 491-92). Sobre la relación que mantuvo a lo largo de su vida Descartes con los jesuitas, sobre todo de la Flèche, ver el artículo de Schmaltz 1999: 38.

21. Al razonamiento circular se le denomina también petitio principii, expresión que traduce una frase utilizada por Aristóteles en relación a un juego dialéctico en el que se produce una disputa de tipo formal, juego practicado en la Antigüedad clásica.

22. Es importante señalar que Aristóteles emplea el término griego syllogismós en dos sentidos diferentes. En un sentido amplio, syllogismós es equivalente a deducción. El Estagirita proporciona una célebre definición de syllogismós entendido como deducción en An. Pr. I 1 (24b 18-20). Para Barnes, la definición de syllogismós puede ser representada de la siguiente manera: $A_{1}, A_{2} \ldots A_{n} \vdash B$, donde $n$ es mayor que 2 y B es distinto de todos los A (Barnes 1969, p. 129). En un sentido más restringido, syllogismós tiene el mismo significado que nosotros damos habitualmente a este 


\section{RAFAEL CERPA ESTREMADOYRO}

término en castellano (véase la definición proporcionada arriba). A esto, se añade el empleo por parte del filósofo griego de un término aún más general que syllogismós en cuanto deducción, que sería equivalente a inferencia o deducción en el sentido contemporáneo de un argumento deductivamente válido. Aristóteles utiliza para denotarlo la palabra griega anagkaion ('necesidad'), que en el contexto de los Analíticos primeros puede ser equivalente a inferencia (cf. An. Pr I 32, 47a33-5). Así, todos los silogismos tal como se entiende hoy son casos especiales de syllogismós, mientras que todos los syllogismoí o deducciones son casos de anagkaion o inferencia. Cuando syllogismós se refiera al uso más general, nosotros lo traduciremos usualmente como deducción. En el caso del razonamiento que conduce a la demostración, en griego syllogismós apodiktikós o simplemente apodeíxis, se empleará las expresiones deducción demostrativa o silogismo demostrativo para su traducción, teniendo en cuenta que Aristóteles usa en este contexto syllogismós en un sentido amplio, es decir en tanto deducción. Si a pesar de todo continuamos empleando la traducción incorrecta de silogismo demostrativo, es sobre todo para no causar algún grado de confusión en los lectores acostumbrados a esta versión. También utilizaremos las expresiones deducción o silogismo apodíctico.

23. Un ejemplo paradigmático de silogismo definido de esta manera es BARBARA, un modo de la primera figura:

Todo lo que piensa tiene espíritu

Premisa mayor

El alma piensa

Premisa menor

El alma es espiritual

Conclusión o Pregunta

24. Ver también An. post. I 2, $71 b 18$.

25. La definición de deducción o silogismo demostrativo mencionada aquí aparece en BARNES 1981: 17-60. Sin embargo, a diferencia de Barnes, que presenta una definición recursiva en dos pasos, nosotros hemos considerado tres.

26. "Atqui ut adhuc euidentius appareat, illam disserendi artem nihil omnino conferre ad cognitionem ueritatis, aduertendum est, nullum posse Dialecticos syllogismum arte formare, qui uerum concludat, nisi prius eiusdem materiam habuerint, id est, nisi eandem ueritatem, quae in illo deducitur, iam ante cognouerint [...]"

27. Ver también AT VI 17, AT IXB 13.

28. "Atque in hoc uno Dialecticos imitamur, quod, sicut illi, ad syllogismorum formas tradendas, eorumdem terminos, siue materiam cognitam esse supponunt, ita etiam nos hic praerequirimus, quaestionem esse perfecte intellectam».

29. Descartes no dice claramente por qué él considera que la silogística es circular. El pasaje de la Regla 10 antes mencionado solo dice que lo es. Gaukroger plantea la hipótesis plausible de que él tiene en mente los argumentos, sobre todo escépticos, 


\section{DESCARTES Y LOS INICIOS DE LA LÓGICA FACULTATIVA}

contra la lógica aristotélica en la Antigüedad, tal como aparecen en los Academica de Cicerón (Libro II, XIV-XXX) y en los Esbozos pirronianos de Sexto Empírico (PH, II 134-244). Ver también de este último autor los argumentos en contra del silogismo en Contra los profesores (Adversus mathematicos, II, 300-481).

30. Ambas exposiciones clásicas de la circularidad del silogismo son señaladas también por Gaukroger. Este intérprete recoge las diferentes críticas al silogismo formuladas en la Antigüedad, sobre todo por autores escépticos como Sexto Empírico (cf. Gaukroger 1989: 11-12). Nosotros no seguimos aquí su presentación sobre este tema.

31. Un desarrollo del primer argumento se puede encontrar en el texto de Gaukroger antes mencionado (1989: 11ss), que a su vez sigue en buena parte los aportes dados por J. Barnes sobre este tema.

32. Esta palabra procede de la expresión griega, diallêlôn, que significa «uno por el otro, y el otro por uno». El dialelo no concierne únicamente argumentos o sistemas de más de dos proposiciones, sino que como lo muestran los usos que le da Sexto Empírico se puede aplicar también a definiciones.

33. PH 1.164-177. Ver también DL 9.88-89. Los otros cuatro modos son la regresión al infinito, la hipótesis (o suposición sin proporcionar argumento alguno), el desacuerdo existente tanto entre los puntos de vista filosóficos como los puntos de vista de la vida ordinaria, y la relatividad en relación con el objeto que se juzga y de las cosas observadas junto con él.

Se desconoce quién fue exactamente Agripa, probablemente un filósofo romano que vivió entre el siglo I y el siglo II d.C.

34. La palabra "cosa" puede hacer referencia aquí a la conclusión.

35. Emanaciones puede hacer referencia aquí a la sudoración, visible, que se tiene por un signo de la existencia de poros imperceptibles en la piel. No obstante, Diógenes no dice cómo la existencia de poros invisibles podría ser utilizada para establecer, a la inversa, las emisiones visibles, con el fin de formar la segunda parte de dialelo. Una posible aplicación del ejemplo de Diógenes al caso de los cerdos, donde se emplea emanación en tanto sudoración, véase Sexto Empírico (PH II 140, 142, Ad. Math. VIII 306, 309).

36. BARNES 1995: 91ss. Se trata de la edición italiana de The Toils of Scepticism, publicada en 1988 con el título: Aspetti dello scetticismo antico.

37. Asimismo, el propio Descartes parece haber admitido sin problema que los silogismos podían en verdad «aportar pruebas demostrativas sobre todos los temas» (AT V 175).

38. Se trata de un pasaje que pertenece a la Séptima serie de objeciones, es decir, son las respuestas que da Descartes al jesuita Pierre Bourdin.

39. Las lógicas del descubrimiento son las diferentes metodologías, que permiten la obtención de resultados en la ciencia. Empleamos el plural, pues en realidad existen 


\section{RAFAEL CERPA ESTREMADOYRO}

múltiples métodos de descubrimiento, siendo el más conocido la inducción. De este modo, I. Lakatos (1970: 103ss) menciona cuatro lógicas del descubrimiento: el inductivismo, el convencionalismo, el falsacionismo metodológico de Popper, y su propia propuesta, la metodología de los programas cientificos de investigación. Como hemos visto, los tópicos de Aristóteles pueden ser considerados también como un método del descubrimiento. Es importante notar que, algunas veces, estas lógicas se conciben como auto-excluyentes.

40. "Il m'a dit que Bacon lui a premièrement rendu suspecte la philosophie d'Aristote, et que votre méthode la lui a fait entièrement rejeter» (Carta de la Princesa Elizabeth a Descartes del 21 de febrero de 1647, AT IV, 619). La princesa Elizabeth se refiere al testimonio del médico Weis.

41. Esta interpretación depende de una visión orientada casi exclusivamente a la doctrina cartesiana de las ideas. Como lo señala Gaukroger (1989: 131) este prejuicio se remonta al siglo XVII, siendo los responsables en buena parte Arnauld y Nicole, que proponen en la Lógica de Port-Royal (1662) un modelo geométrico de la invención, que depende en gran medida de la reflexión sobre lo que está contenido en las propias ideas. Este modelo resta importancia a la observación y el experimento, aunque curiosamente Arnauld aboga también por un razonamiento probabilístico (Lógica, IV 23).

42. Se trata de la obra, Cartesian Method and the Problem of Reduction.

43. «unde patet, illos ipsos ex tali forma nihil noui percipere, ideoque uulgarem Dialecticam omnino esse inutilem rerum ueritatem inuestigare cupientibus, sed prodesse tantummodo interdum posse ad rationes iam cognitas facilius aliis exponendas, ac proinde illam ex Philosophia ad Rhetoricam esse transferendam». Este pasaje es la continuación del mencionada en la página Xx («atqui ut adhuc[...]»).

44. Sobre las interpretaciones desacertadas del silogismo a lo largo de buena parte de la historia, ver el trabajo de J. Lukasiewicz La silogística de Aristóteles desde el punto de

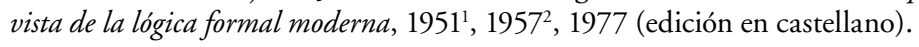

45. Ver la definición de deducción o silogismo demostrativo antes mencionada.

46. Sobre este punto, ver BARNES 1969: 127. Este intérprete proporciona a lo largo de su artículo una serie de pruebas que demuestran lo afirmado arriba.

47. «La teoría de la ciencia demostrativa nunca fue destinada a orientar o formalizar la investigación científica. Se refiere exclusivamente a la enseñanza de hechos ya alcanzados, no describe cómo los científicos operan, o deberían, al momento de adquirir conocimientos. La demostración ofrece un modelo formal de cómo los maestros deben impartir conocimiento» (Barnes 1969: 138). cf. Barnes 1975, pp. 65-87; se trata de una versión revisada de un artículo publicado originalmente en 1969 en la revista Phronesis. 


\section{BIBLIOGRAFÍA}

ARIEW, Roger

2006 [1992]

«Descartes, les premiers cartésiens et la logique». Revue de métaphysique et de morale, 1. a ed., N. 49, pp. 55-71.

Aristóteles

1924

1951

Aristotle's Metaphysics. Edición crítica de William David Ross. Oxford: Clarendon Press.

Aristotle's Prior and Posterior Analytics. Edición crítica de William David Ross. Oxford: Clarendon Press.

1996

Posterior Analytics. Traducción y comentario de Jonathan Barnes. Clarendon Aristotle Series. Oxford: Clarendon Press.

BARNES, Jonathan 1969 "Aristotle's Theory of Demonstration». Phronesis, N. 14, pp. 123-152.

1975 "Aristotle's theory of demonstration». En BARNES J., Schofield M. y R. Sorabji (eds.). Articles on Aristotle, Vol. N. 1, Science, London, Duckworth, pp. 65-87. 
1981

1990

I995 [I988]

«Proof and the Syllogism». En Berti, Enrico y Mario Mignucci. Aristotle on Science, the Posterior Analytics. Padua: Antenore, pp. 17-60.

The Toils of Scepticism. Cambridge: Cambridge University Press.

Aspetti dello scetticismo antico. Traducción de Leda Papa. Nápoles: La Città del Sole.

Buickerood, James G. I 985

"The Natural History of the Understanding: Locke and the Rise of Facultative Logic in the Eighteenth Century». History and Philosophy of Logic 6, 1. ${ }^{\text {e }}$ d., pp. 157-190.

Charrak, André 2005 "La critique du syllogisme dans Bacon et Descartes». Les études philosophiques, 4. ${ }^{\mathrm{a}}$ ed., N. 75, pp. 469484.

Clarke, Desmond 2006

Descartes: A Biography. Cambridge: Cambridge University Press.

Cook, Roy T.

2009

A dictionary of philosophical logic. Edinburgh: Edinburgh Univ. Press. 
Cottingham, John

1992

1993

1995

Descartes, René

1964-1976

1996

Diógenes LAERCio 1999

GARBER, Daniel

2000
The Cambridge companion to Descartes. Cambridge: Cambridge university press.

A Descartes dictionary. Cambridge (Mass.):

Blackwell reference.

Descartes. Versión de Laura Benítez et al. Ciudad de México: FFYL-UNAM.

Oeuvres de Descartes. Revisión y edición de C. Adam y P. Tannery (abreviado como AT). Paris: Vrin y CNRS.

Reglas para la dirección del espiritu. Introducción, traducción y notas de Juan Manuel Navarro Cordón. Madrid: Alianza editorial.

Vitae Philosophorum. Edición de Miroslav Marcovich. 2 vols. Vol. I: Libri I-X; Vol. II: Excerpta Byzantina. Stuttgart y Leipzig: B.G. Teubner.

Descartes Embodied: Reading Cartesian Philosophy through Cartesian Science. New York: Cambridge University Press. 
GaUkroger, Stephen I 989

Cartesian logic: An Essay on Descartes's Conception of Inference. Oxford: Clarendon Press.

Grosholz, Emily I99 I

Cartesian Method and the Problem of Reduction. Oxford: Clarendon Press.

LAKATOS, Imre I 970

«History of Science and Its Rational Reconstructions». PSA: Proceedings of the Biennial Meeting of the Philosophy of Science Association, Vol. 1970, pp. 91-136.

LUKASIEWICZ, Jan 1957

La silogística de Aristóteles desde el punto de vista de la lógica formal moderna, 1951a, 1957b, 1977 (edición en castellano). Madrid: Editorial Tecnos.

Orcibal, Jean I 953

"Qu'estce que le jansénisme?». Cahiers de I'association internationale des études francaises, Vol. 3, N. 3-5, pp. 39-53.

Risse, Wilhem

I 964-I 970

Die Logik der Neuzeit (La lógica de los tiempos modernos). 2 Vols. Stuttgart: Bad Cannstatt \& Fromann. 
RodIs LEWIS, Geneviève I995

Descartes, Biographie. Paris: Calmann-Lévy.

SAVINI, Massimiliano 2006 «L'insertion du cartésianisme en logique: la Logica vetus \& nova de Johannes Clauberg». Revue de métaphysique et de morale, Año 1, N. 49, pp. 7388.

Schmaltz, Tad M.

I996

"What has Cartesianism to do with Jansenism?». Journal of the History of Ideas, 1. a ed., N. 60, pp. 37-56.

SÉRIS, Jean-Pierre 1993

"Language and Machine in the Philosophy of Descartes». En Voss, Stephen (ed.). Essays on the Philosophy of Science of René Descartes. Oxford: Oxford University Press.

SEXTO EMPíRICO 1958

Sexti Empirici Opera. Recensuerunt Hermannus Mutschmann et Jurgen Mau. Leipzig: Teubner. 